\title{
Aproximación al pensamiento político de Donald Trump: ¡es el presidente de Estados Unidos populista?
}

\author{
An approach to Donald Trump's political thought: \\ Is the US President a populist?
}

\author{
ALFREDO RAMÍREZ NÁRDIZ \\ Universidad Libre, Barranquilla (Colombia)
}

\section{Cómo citar/Citation}

Ramírez Nárdiz, A. (2020). Aproximación al pensamiento político de Donald Trump: ¿̇es el presidente de Estados Unidos populista? Revista Española de Ciencia Política, 52, 59-83. Doi: Disponible en: https://doi.org/10.21308/recp.52.03

\section{Resumen}

Tanto la campaña de las elecciones presidenciales de los Estados Unidos de 2016 como la posterior presidencia de Donald Trump han supuesto, en diversos aspectos, una ruptura con las prácticas, usos, modos y formas tradicionales en la política occidental. La apelación constante a los sentimientos (y las bajas pasiones) de los votantes, la relativización de los hechos, las declaraciones racistas, xenófobas, machistas y hostiles a las minorías, la política interior rupturista con el pasado y la política exterior grandilocuente han sido elementos de una acción de gobierno habitualmente calificada como caótica e impulsiva, cuando no infantil o irracional. Se suele acusar al presidente Trump de populista. Este artículo pretende ofrecer una aproximación a su pensamiento político y contrastarlo con una serie de elementos que se proponen como característicos del populismo. Esto permitirá valorar la medida en que el actual inquilino de la Casa Blanca puede o no ser considerado populista, y se llega a la conclusión de que es posible hacerlo.

Palabras clave: Donald Trump, pensamiento político, presidente, populismo, Estados Unidos.

\begin{abstract}
Both the 2016 US presidential election campaign and Donald Trump's later presidency have entailed, in several aspects, a break with the traditional practices, uses, modes and forms in Western politics. The constant appeal to voters' feelings (and low passions), the relativization of facts, the racist, xenophobic, sexist statements and those others hostile to minorities, a home policy rupturist with the past and a grandiloquent foreign policy have all been elements of a government action usually described as chaotic and impulsive, or even as childish and irrational.
\end{abstract}


President Trump is usually accused of being a populist. This article aims at offering an approach to Trump's political thought checking it against a series of elements deemed characteristic of populism. This will, in turn, allow to assess the extent to which the current host of the White House can be considered as a populist or not. Ultimately, the conclusion is reached that it is certainly possible to do so.

Keywords: Donald Trump, political thinking, president, populism, United States.

\section{INTRODUCCIÓN}

¿Cuál es la ideología de Donald Trump? Ante el aparente desorden que muchas veces muestran su discurso y sus decisiones, donde no son extraños los cambios de opinión y las contradicciones, cabría pensar que Trump no posee una ideología determinada y que no hace más que adaptarse a lo que considera más apropiado para sus intereses coyunturales. Pero, salvo que se renuncie a la búsqueda de racionalidad en el pensamiento del presidente de EE. UU., parece relevante tratar de elaborar un mínimo cuadro de la ideología del actual titular de la presidencia norteamericana. En los intentos de establecer la ideología de Trump es recurrente escuchar a modo de diagnóstico la palabra populismo. Se suele describir al presidente de EE. UU. como un populista. Como tal, se le incardina en un conjunto más o menos difuso de partidos y líderes políticos de reciente aparición a ambos lados del Atlántico, en ocasiones considerados de extrema derecha, en ocasiones de extrema izquierda,

¿Pero qué es ser populista? ¿Puede serlo igualmente un partido que se identifica, o que es identificado, con la derecha y uno que lo hace con la izquierda? ¿Cuáles son los rasgos que caracterizan el populismo para poder afirmar que Trump lo es o no lo es? ¿Existe siquiera el populismo o no es más que un término peyorativo que a fuerza de repetirse se ha popularizado y que no es utilizado más que como epíteto para descalificar al rival político? ¿Se puede aceptar, como indica Laclau (2005: 32), que la palabra populismo suele ser usada de modo vago, sin contenido y con afán denigratorio para referirse a movimientos dispares? Este texto pretende ofrecer una caracterización del pensamiento de Trump que permita identificar o no al presidente de los EE. UU. como un populista, tratando, además, de dar respuesta a las preguntas arriba citadas.

Es decir, se busca aportar una propuesta de definición y una enumeración de las características del populismo desde la cual calificar o no a Trump como populista. Metodológicamente, se parte de analizar tanto los principales rasgos del pensamiento de Trump como de aquellos elementos que se plantean como propios del populismo para, a continuación, enfrentar unos con otros, tratando de dilucidar la existencia o no existencia de similitudes entre los primeros y los segundos. Esto es, se elabora una sucinta enumeración de los rasgos que definen la ideología de Trump en función de sus promesas electorales presentadas a las elecciones presidenciales de 2016, de su acción de gobierno desde entonces y de las declaraciones que ha hecho en su devenir político reciente. A continuación, se ofrece una propuesta de enumeración de elementos del 
populismo, apoyada en un análisis de la doctrina más conocida en la materia. Finalmente, se compara la primera con la segunda, para poder concluir si el presidente de EE. UU. es o no un populista en función de que exista o no identificación entre las dos. Las respuestas que se alcanzan no prentenden ser absolutas, sino apenas una puerta abierta al debate tanto de la ideología de Trump como del concepto de populismo.

\section{IDEOLOGÍA DE DONALD TRUMP}

¿Cuáles son los distintos elementos de la ideología de Trump? Partiendo de sus promesas electorales, de sus declaraciones en la campaña electoral de 2016, así como de sus actuaciones durante su mandato, se pueden proponer los siguientes rasgos ideológicos de Trump.

\section{Reacción}

La ideología de Trump es esencialmente reactiva; es decir, de oposición a otros movimientos y corrientes, generalmente considerados progresistas por cuanto consistían en la ampliación o reconocimiento de derechos de minorías (hispanos, negros, musulmanes, inmigrantes o refugiados. Como indican Bassets y Faus (2017), la entrada de refugiados y ciudadanos de países musulmanes como Siria, Yemen o Irak fue vetada nada más llegar Trump al poder, o de grupos infrarrepresentados como las mujeres. La ideología de Trump es reactiva como reactiva se puede considerar también a la llamada derecha alternativa (alternative right o alt-right) estadounidense, con la que se suele identificar a Trump. Así, para Almansa (2019: 167-169), aunque Trump tiene un perfil propio frente a dicha derecha alternativa, forma parte de un mismo fenómeno anti-establishment con ella: el de quienes se consideran traicionados por un Partido Republicano demasiado cercano al Partido Demócrata y que ha asumido concepciones de la izquierda como el multiculturalismo, la aceptación de la creciente inmigración y la integración de los EE. UU. en la economía globalizada. Trump puede parecer un supremacista cultural, xenófobo, racista o machista; pero ninguno de estos rasgos será más que la manifestación del verdadero fondo de su pensamiento, que no es otro que la reacción a todo lo que en su conjunto se ha llamado ideología progresista. Ante una sociedad estadounidense cada vez menos blanca, anglosajona, protestante y masculina, y caracterizada, en cambio, por un mayor pluralismo cultural, religioso y racial, las declaraciones de Trump reflejan la nostalgia de las esencias de la América WASP (white, anglo-saxon, protestant) supuestamente perdida. Trump encaja en la corriente populista estadounidense que critica a las élites en nombre del pueblo, pero entendiendo a dicho pueblo como aquellos de herencia europea (Kazin, 2016).

Las declaraciones y actuaciones en este sentido abundan; así, por ejemplo, son xenófobas frente a los extranjeros, en general, y los mexicanos, latinoamericanos y procedentes de países musulmanes más en particular. Como indica Qiu (2016), desde 
2015, y tras el tiroteo de San Bernardino, Trump pidió un «total y completo cierre a la entrada de musulmanes en EE. UU.». También tienen connotaciones racistas, como cuando en un debate presidencial Trump mostró a la población afroamericana como propensa a la delincuencia al afirmar que «afroamericanos e hispanos viven en el infierno. Caminas calle abajo y te disparan» (citado por Chan, 2016). Y pueden calificarse de machistas bien por ver a las mujeres como objetos sexuales - a su propia hija le otorgó un 10 en una hipotética clasificación de belleza femenina (Moye, 2018)—, bien por denigrarlas por su comportamiento o apariencia física, como hizo en las declaraciones del autobús de 2005 en las que afirmó que, debido a su fama, podía hacer lo que quisiera con una mujer, incluso cogerla por su sexo (La Vanguardia, 2016), o el incidente con la ex Miss Universo Alicia Machado, a la que llamó asquerosa en Twitter y, según ella, también Srta. Peggy, por la cerdita de The Muppet Show, o Srta. Limpiadora (Ayuso, 2016).

Este modo agresivo de expresarse se desarrolló especialmente durante la campaña electoral de 2016 y puede enmarcarse en la actitud general de Trump hacia todos sus adversarios, tanto rivales políticos - lo sufrieron especialmente Jeb Bush y Ted Cruz en los republicanos (Broomfield, 2016) o Hillary Clinton entre los demócratas (Woolf, 2016) - como cualquier sujeto, comunidad o país al que ubique como antagonista, a los que tiende a denigrar y ridiculizar. En contraste, basta con observar su actitud frente al supremacismo blanco. Así, tras los incidentes de Charlottesville, en los que hubo marchas del Ku Klux Klan y contramarchas, con un incidente donde incluso un coche envistió contra una contramarcha causando la muerte de una persona, Trump equiparó a los supremacistas blancos (entre los cuales dijo que había mucha buena gente) con quienes protestaban contra ellos (Cilizza, 2017a). Esto sugiere que el modelo de sociedad que encarna es una reacción frente a aquella otra sociedad plural que se abre camino en EE. UU.: la reacción de los hombres blancos anglosajones que se consideran desplazados y maltratados por la globalización y las transformaciones que esta supone (Almansa, 2019: 173-174). Para Lowndes (2016: 100) la imagen del populista estadounidense es la de un hombre blanco agraviado, desplazado de la centralidad en la política, en el trabajo y en el hogar. No obstante, el apoyo a Trump no solo procede de los trabajadores objetivamente empobrecidos por la globalización, sino de aquellos que subjetivamente se sienten empobrecidos y olvidados por ella. Entre sus votantes caben muchos más que aquellos realmente perjudicados por la globalización: clases medias blancas y heterosexuales que sienten que mujeres y minorías raciales y sexuales obtienen más beneficios sociales que ellos (De la Torre, 2018: 183).

\section{Proteccionismo económico y aislacionismo}

Trump ha defendido la necesidad de renegociar o salir de los tratados internacionales de libre comercio que EE. UU. ha suscrito, al considerar que los mismos les perjudican. No es tanto que Trump se oponga al libre comercio internacional en sí, sino que se opone a la forma en la que este se había desarrollado hasta su llegada a la presidencia 
(Smith, 2016: 104). El NAFTA con Canadá y México ha sido objeto de sus críticas; por ejemplo, en la campaña electoral de 2016 anunciaba: «Voy a decirles a nuestros socios del NAFTA que pretendo renegociar inmediatamente los términos de ese acuerdo para conseguir un mejor trato para nuestros trabajadores. Y no quiero decir solo un poco mejor, quiero decir mucho mejor» (citado en Tani, 2016). También ha criticado las políticas deslocalizadoras de las grandes empresas estadounidenses, así como la posición ventajosa que, en su opinión, tienen los productos alemanes o chinos en EE. UU., llegando a afirmar que «hay gente que desearía que no me refiriese a China como nuestro enemigo. Pero eso es exactamente lo que son» (citado por Stracqualursi, 2017). Desde estas consideraciones, ha promovido la salida de EE. UU. del Acuerdo Transpacífico de Cooperación Económica, de la UNESCO y ha manifestado su deseo de sacar a EE. UU. del Acuerdo de París sobre el Cambio Climático (Trump, 2017).

\section{Unilateralismo y militarismo}

Trump ha urgido a los países de la OTAN a asumir mayores gastos en defensa, sugiriendo la posibilidad de que EE. UU. se inhiba si alguno de los miembros de la Alianza es atacado por un tercero (Raymond, 2018). Esto lo ha simultaneado con una política exterior agresiva, abierta siempre a la opción militar (incluso nuclear, frente a Siria, Irán o Corea del Norte) y muchas veces contradictoria, en la que se pasa de la amenaza y el insulto a la cordialidad y el halago. Así, por ejemplo, en relación con China se ha afirmado que EE. UU. se retirará de Asia, para a continuación negarlo; o se critica a la nación asiática, para después manifestar admiración por su líder. Como ha argumentado Abad (2017: 322), el estilo negociador de Trump parte de establecer unas exigencias muy duras, creando un escenario de tensión, para después rebajarlas, aparentar dar concesiones y así conseguir los resultados favorables buscados desde el principio.

No se puede olvidar su propuesta estrella de construir un muro con México; así, desde el comienzo de la campaña electoral en 2016, prometió «construir un gran muro en la frontera sur» y «hacer que Méjico pague por ese muro» (Qiu, 2016). En conjunto, plantea una política exterior que abandona la visión de los EE. UU. como fuerza hegemónica en el mundo, máximo defensor y beneficiario de la globalización, para asumir otra en la que EE. UU. actúa como potencia imperial que interviene en el exterior exclusivamente movida por sus intereses particulares. No es tanto que Trump sea un aislacionista puro, aunque atribuya todos los problemas de EE. UU. a terceros países, sino que desea un enfoque de la política exterior estadounidense diferente al globalista y de tipo imperialista, que no busca el liderazgo, sino la dominación (Smith, 2016: 101-106).

\section{Negacionismo y antiintelectualismo}

Trump se ha caracterizado por relativizar la objetividad y tratar de crear su propia concepción subjetiva de la realidad, con la pretensión de que sea igualmente respetable 
que la objetiva y procedente de los datos probados ${ }^{1}$. Ello puede observarse en su relación frente a la comunidad científica al negar el cambio climático, con expresiones como «no soy un creyente en un calentamiento global hecho por el hombre» (citado en Cillizza, 2017b). También en su relación frente a los medios de comunicación, al relativizar los hechos y poner en igualdad las noticias con los rumores, las teorías conspirativas o las mentiras. La expresión "hechos alternativos» ganó fama cuando la asesora presidencial Kellyanne Conway la utilizó para justificar unas palabras del portavoz presidencial que habían sido acusadas de ser falsas (CNN, 2017).

Trump no apela a la razón de los ciudadanos, sino a sus emociones (a menudo a las negativas, como el racismo y la xenofobia) en un intento de establecer con ellos una vinculación emocional impermeable a cualquier crítica argumentada. Apunta Lowndes (2016: 99) que esta vinculación que Trump establece con los votantes se construye sobre identificaciones emocionales en las que Trump interrelaciona elementos sensibles para dichos votantes: la ansiedad que generan los temas raciales con la precariedad económica, la masculinidad, el abandono sufrido por las élites políticas, etc. Una manifestación del antiintelectualismo de Trump es la consciente y constante voluntad de ser políticamente incorrecto, de enfrentarse a los usos cultos y civilizados recurriendo a expresiones groseras, vulgares y denigrantes para las minorías, en la concepción de que así se visibiliza el enfrentamiento con las élites y se produce la identificación con un supuesto hombre sencillo que se expresa y comporta de un modo normal (Almansa, 2019: 169). El contraste en el modo de expresarse en las elecciones presidenciales de 2016 de Clinton (seria, inteligente, sensible) y de Trump (intimidatorio, grosero, despreciativo) muestra la diferencia entre el lenguaje atribuido a las élites y el politicamente incorrecto utilizado por los populistas (Moffitt, 2016: 55).

\section{Personalismo, caudillismo, mesianismo, paternalismo ${ }^{2}$}

Frente al lema de Obama, Yes, we can («Sí, podemos»), que manifestaba su propuesta de un pacto social transversal para mejorar la sociedad estadounidense, Trump se caracterizó durante la campaña presidencial de 2016 por presentarse a sí mismo como el único individuo capaz de solucionar todos los problemas del país. Para ello, se identificó con el «hombre medio» americano, víctima de los poderosos, de los medios de comunicación y de las élites económicas, políticas e intelectuales, y se presentó como la única herramienta que tienen los maltratados hombres buenos

1. Si dicho antiintelectualismo se debe a una consciente voluntad de identificarse con el pueblo frente a la élite o si es algo derivado de la escasa preparación intelectual de Trump, hace de interés el análisis de Mena (2018: 51-57) cuando destaca que habitualmente Trump se expresa con palabras de escasas sílabas (una, dos, tres, rara vez cuatro), repite mucho unas pocas ideas, ordena las frases mediante yuxtaposición sin usar subordinadas, se expresa de un modo inarticulado y caótico, etc.

2. Mena (2018: 62). 
para recuperar sus puestos de trabajo perdidos, su sociedad rota y su dignidad pisoteada. Así, afirmó: «Os lo daré todo. Soy el único. Yo solo puedo arreglarlo» (citado por Politico Magazine, 2016). En la misma línea, en la Convención del Partido Republicano de 2016 declaró: «Estos son los hombres y mujeres olvidados de nuestro país. Gente que trabaja duro pero que ya no tiene una voz. Yo soy vuestra voz» (citado por Hawkins, 2016: 95). Trump materializa de este modo el elemento más tradicionalmente populista: la lucha del pueblo y del hombre sencillo contra las élites que abusan de él. Con todo, para Lowndes (2016: 100) Trump no es tanto un campeón de la clase trabajadora frente a las élites, como sí fue habitual en pasadas oleadas populistas en EE. UU., sino que el presidente se muestra sobre todo como una figura que confirma el estatus degradado de estas clases trabajadoras, y cuyos seguidores responden menos a llamados por su condición de trabajadores que a la rabia brutal contra las élites, los inmigrantes, los musulmanes o los negros, a quienes consideran causantes de su miseria.

En función de estas características y asumiendo la complejidad que proporciona un líder capaz de pasar en apenas unas pocas semanas de una opinión a la contraria - así ocurrió en el caso de Corea del Norte que, de recibir amenazas de destrucción, "fuego y furia como el mundo nunca ha visto», pasó a ser reconocida como interlocutor válido con el que mantener reuniones cordiales (Bierman, 2017) —, puede afirmarse que la ideología de Donald Trump se resume en una sola palabra: reacción. Es una ideología reaccionaria, si por tal se entiende aquella que reacciona frente a otra previa y que trata de revertir gran parte, si no la totalidad, de las transformaciones políticas, económicas y sociales realizadas en la presidencia anterior. Frente a los años de Obama, en los que se apostó por el internacionalismo, los derechos sociales o la lucha contra el cambio climático, la presidencia de Trump parece en ocasiones no tener más objeto que derrumbar todo lo hecho por su antecesor: oposición al Obamacare (Martín, 2017), salida del Acuerdo de París sobre el Cambio Climático, ruptura del pacto nuclear con Irán, etc. (Eilperin y Cameron, 2018).

No obstante, afirmar que Trump es el opuesto perfecto a Obama sería un enfoque excesivamente centrado en el personaje, en sus filias y fobias personales porque, más allá de las personas, la ideología que Trump encarna es la respuesta frente a aquella que Obama personificó. Así, frente a una visión del mundo enmarcada en las dinámicas globalizadoras, aparece un movimiento reactivo que pretende cerrar todo lo que la globalización abre. Frente a un Obama que simboliza -incluso personalmente-el cosmopolitismo y el triunfo de las minorías, Trump defiende alzar muros, físicos, económicos y sociales, que detengan la apertura que la globalización implica. En sus propias palabras, "americanismo, no globalismo, será nuestro credo" (citado por Smith, 2016: 101).

La ideología de Trump es la reacción. La negación de los cambios producidos en las últimas décadas, que han llevado a una mayor interconexión mundial a nivel internacional (tanto política, como económica) y a una mayor aceptación de la heterogeneidad (racial, sexual, religiosa) a nivel nacional. Es posible ubicar esta ideología reaccionaria en distintas opciones políticas a ambos lados del Atlántico: Trump en los 
EE. UU. o diversos partidos europeos que ya en Alemania (AfD), Francia (Frente Nacional) o Italia (Liga) abogan por revertir gran parte de las transformaciones generadas por la globalización en aspectos económicos (libre comercio), políticos y sociales (inmigración), retornando a un mundo previo a dichas transformaciones. Para Trump: «La globalización ha hecho muy rica a la élite financiera, pero ha dejado a millones de nuestros trabajadores sin nada salvo pobreza y dolor de corazón» (Diamond, 2016).

La ideología de Trump puede causar estupor en gran parte del público conocedor de los datos objetivos acerca de los progresos que el mundo está haciendo en el periodo histórico al que genéricamente se llama globalización ${ }^{3}$, pero conecta bien con otra parte del público al que se suele considerar perjudicado por la globalización: clases medias y bajas que temen por su futuro económico y clases medias y altas sin miedos económicos, pero si culturales y sociales. En el primer caso, personas con bajo nivel de estudios, desempleadas o con empleos mal retribuidos, a los que les preocupan sus ingresos y los de sus hijos ante la llegada de inmigrantes y que sienten debilitarse sus derechos sociales bajo la presión de una economía globalizada. En el segundo, personas que creen perder la hegemonía del grupo social, racial, sexual o religioso del que forman parte, o desvanecerse el modelo de sociedad en el que creen, y a los que sienten amenazados por extranjeros, minorías, feminismo, etc. En ambos casos, personas que se consideran abandonadas por las élites cosmopolitas y que canalizan su frustración en el voto a opciones políticas alternativas que les permiten visualizar un enemigo al cual culpar de las circunstancias que les atenazan eximiéndose a sí mismos de toda responsabilidad, que les dan respuestas sencillas a problemas complejos y que les ofrecen líderes que les prometen un futuro mejor mediante una vuelta al pasado perdido.

No cabe, sin embargo, ignorar que Trump, aun y debiendo ser entendido en el contexto histórico al que pertenece, puede ser considerado heredero de la tradición populista estadounidense que encuentra algunos de sus hitos en figuras como la del presidente Andrew Jackson ${ }^{4}$ en el primer tercio del xix, o el People's Party a finales de

3. Frente a la conceptualización positiva que de la globalización se transmite desde este texto, quepa recordar como contraste el conocido trilema de Rodrick (2012: 20), que señala que no se puede conseguir simultáneamente democracia, autodeterminación nacional y globalización económica.

4. Jackson suele citarse como origen del populismo estadounidense. Durante su mandato, y frente al Congreso, concibió la presidencia como verdadera representación del pueblo estadounidense; por ello, la fortaleció frente al Congreso, la judicatura y el resto de instituciones del Estado, transformándola desde lo meramente administrativo a lo tribunicio (Aguilar, 2019: 68). Anticipó así uno de los rasgos más típicos del populismo, el del líder que, frente a unas élites políticas y económicas corruptas, se erige en portavoz del ciudadano sencillo frente a un enemigo común, el «poder del dinero» (Feller, 2019).

5. Partido procedente mayoritariamente del sur y el oeste de los EE. UU. que ensalzaba a los trabajadores rurales y urbanos, el «pueblo llano», mientras atacaba a las élites de las altas finanzas y la industria por empobrecerlos. En 1892 el partido logró veintidós votos electorales en las elecciones presidenciales con su candidato James Weaver para declinar en los siguientes años. 
dicho siglo. Para Mead (2016), puede que la elección presidencial de Trump fuera una sorpresa, pero el movimiento que le condujo a la victoria no es nuevo, sino que hunde sus raíces en la historia estadounidense, siendo sus seguidores los herederos de aquellos que apoyaron al presidente Jackson, personas que no solo sienten descontento económico y que rechazan una dirección tecnócrata y elitista del Estado, sino que ven los cambios que sufre su país (como el vuelco demográfico a una sociedad menos blanca y más multiétnica) como una declaración de guerra. Mead (2017) atribuye a Trump haber percibido en la sociedad estadounidense el auge del populismo nacionalista jacksoniano, esto es, del sentimiento de la América jacksoniana de estar bajo sitio, con sus valores atacados y su futuro amenazado tanto por las élites cosmopolitas (de ambos grandes partidos) como por los inmigrantes y otras minorías que, en conjunto, se han apoderado del gobierno y están transformando la esencia de los EE. UU.

Por tanto, situar a Trump como un nuevo hito en la evolución del populismo histórico estadounidense puede resultar apropiado ${ }^{6}$ en el sentido de considerarlo como alguien que se presenta como un campeón de las clases populares, y en especial de la América WASP, frente a los denunciados atropellos de las élites, pero sin perder de vista que su emergencia, teniendo antecedentes típicamente estadounidenses, obedece igualmente a razones específicamente contemporáneas derivadas de la globalización y sus efectos. Resulta significativo, en el contexto de este choque entre clases populares y élites, que haya figuras como la ex secretaria de Estado Albright (2018: 5) que consideren a Trump como el presidente de los tiempos modernos cuyas afirmaciones y acciones están más en desacuerdo con los ideales democráticos.

\section{PROPUESTA DE CARACTERÍSTICAS DEL POPULISMO}

Vista sucintamente la ideología de Trump y para poder afirmar si la misma se identifica o no con el populismo, es imprescindible tratar de caracterizar el populismo para posteriormente compararlo con el pensamiento de Trump. Ya se considere que el populismo surge a causa del resentimiento económico de los perdedores de la globalización, ya se opte por verlo como una reacción conservadora ante los cambios culturales de corte liberal introducidos en las últimas décadas, ya se afirme

Posiblemente, el heredero contemporáneo del tipo de populismo representado por este partido sea el senador Bernie Sanders, mientras que Donald Trump encaje mejor en otro tipo de populismo racista-nacionalista también surgido a finales del xix en estados como California, con partidos como el Workingmen's Party of California y su rechazo a los inmigrantes asiáticos (Kazin, 2016).

6. No lo es, sin embargo, para autores como Cheathem (2017), que consideran que los paralelismos establecidos entre ambas figuras (que él tiene por falsos) han sido especialmente promovidos por el propio Trump y su círculo para interesadamente fomentar la imagen del empresario neoyorquino como defensor del pueblo frente a las élites del modo en que generalmente se asume que lo fue el presidente Jackson. 
que es la respuesta ante el abandono al que las élites someten al pueblo, el mal funcionamiento de la representación y el incumplimiento de los derechos fundamentales de los ciudadanos, especialmente la igualdad ante la ley (Hawkins, 2016: 95-96), se puede afirmar que hay dos aproximaciones valorativas esencialmente opuestas sobre el populismo. La primera considera que el populismo es un fenómeno positivo, inherente a la democracia, que permite limitar el poder de las élites devolviéndoselo al pueblo. Según la segunda, el populismo promete lo anterior, pero lleva al autoritarismo, a la exclusión de las minorías y a la perversión de la democracia (Bonikowski y Gidron, 2016: 11). Indica Ivarsflaten (2016: 50), citando a Mudde y Rovira (2013), que existe un enfoque intermedio según el cual el populismo tiene dos caras: una que dota al pueblo de poder frente a las élites y otra que debilita las instituciones representativas y el pluralismo. En este trabajo se adopta el segundo enfoque; esto es, se plantea el populismo como una perversión de la democracia.

A continuación, se ofrece una enumeración de los rasgos del populismo más recurrentemente citados y que, sujetos a debate, permiten caracterizarlo (Ramírez Nárdiz, 2018: 153-179).

\section{El líder carismático}

El populismo se apoya en la legitimidad carismática del líder (Mudde, 2004: 556). Establece una fuerte relación entre el pueblo y el líder al que, excediendo sus funciones constitucionales concretas como jefe de Estado o de Gobierno, concibe como voz del pueblo — «no soy yo, soy el pueblo», dirá Chávez- (De la Torre, 2018: 185), y personificación del mismo (Mudde y Rovira, 2017: 43) y lo caracteriza como un caudillo, un salvador o un mesías. El líder suele asumir un rol hipermasculinizado, machista, fuerte, resolutivo, viril y confrontador (De la Torre, 2018: 187), como si de un macho alfa de carácter tribal se tratara. No es por ello sorprendente que el líder populista casi siempre sea un hombre, rara vez una mujer. La identificación que se produce entre el líder y el pueblo lleva a que las manifestaciones del líder se consideren la voluntad del pueblo.

Por ello, cualquier opinión divergente — bien proceda de la oposición, de otra institución política o de la prensa - se asumirá como contraria al pueblo y malintencionada —dice Erdogan: «Nosotros somos el pueblo. ¿¿Quién eres tú?» (Müller, 2016b: 61) - . Al darse esta identificación entre líder y pueblo, cualquier ejercicio de control sobre el líder, particularmente de la oposición parlamentaria, queda anulado a efectos prácticos (Weyland, 2001: 12). El líder es para el populismo el eje en torno al que se unifican en una única voluntad todas las demandas y sensibilidades del pueblo. Laclau se refiere a este proceso como la emergencia del líder: «El populismo emerge, asociando entre sí estas tres dimensiones: la equivalencia entre las demandas insatisfechas, la cristalización de todas ellas en torno de ciertos símbolos comunes y la emergencia de un líder cuya palabra encarna este proces» (2006: 58). 


\section{El pueblo como unidad}

Se crea la ilusión de concebir al pueblo como una unidad sin divisiones, ni fragmentaciones (Müller, 2016: 3-4, 28). No hay distintas sensibilidades ni intereses, sino un único pueblo que, en función de la idéntica racionalidad de todos sus miembros, no puede más que constituirse en una voluntad única que por necesidad debe ser buena, debe tener la razón y de la cual el líder se erige como intérprete necesario. La virtud del pueblo, frente a la maldad de la oligarquía, es uno de los pilares del populismo y puede rastrearse en los primeros partidos que recibieron la denominación de populistas, como el People's Party de finales del xIx en los EE. UU. (Rivero, 2017: 33-34). La visión unitaria del pueblo, en realidad, no es otra cosa que una apariencia generada por una fracción que pretende que el todo se identifique con ella para servirse así de su legitimidad (Laclau, 2005: 214).

El populismo afirma que sobre el pueblo se ciernen amenazas internas y externas que tratan de aprovecharse de él, perjudicarlo o incluso destruirlo. Frente a estas amenazas, el populismo y su líder se ofrecen como medio de protección. El pueblo acostumbra a ser identificado con unos elementos determinados (dependiendo del país: idioma, raza, religión, cultura, etc.) que llevan a que todos aquellos que no los cumplan sean, en la práctica, expulsados o no aceptados en él. Este es el caso de los extranjeros, inmigrantes o refugiados, que buscando integrarse en la comunidad receptora son tenidos como extraños, como enemigos del pueblo, como no pueblo. En palabras de Trump, «la cosa más importante es la unificación del pueblo porque el otro pueblo no vale nada» (Müller, 2016a: 22; ver también De la Torre, 2018: 185). Se fomenta una oposición en la que el líder dirige al pueblo contra el no pueblo (Krauze, 2017: 17) y en la que se generan rupturas entre los grupos sociales, distinguiendo a unos como virtuosos y a otros como corruptos (Bonikowski y Gidron, 2016: 11).

\section{La apelación al pueblo}

La relación entre el líder y el pueblo se materializa en la recurrente solicitud que el primero hace al segundo para que se pronuncie. Indica De la Torre (2018: 181) que Chávez, Correa y Morales «gobernaron a través de campañas y de elecciones permanentes [...]. Los venezolanos votaron en dieciséis elecciones entre 1999 y 2012, los bolivianos en nueve entre 2005 y 2016 y los ecuatorianos en once entre 2006 y 2013». La apelación al pueblo se hace generalmente mediante la tergiversación de los instrumentos de la democracia participativa, particularmente las preguntas directas a la ciudadanía como referendos (Ivarsflaten, 2016: 50) y plebiscitos, para legitimar el poder del líder frente al de las restantes instituciones del Estado. Estos instrumentos participativos, especialmente en los ámbitos municipales, no se utilizan para mejorar la democracia, sino para establecer relaciones clientelares en las que los ciudadanos autónomos acaban convertidos en masas agradecidas (De la Torre, 2013: 127-129). 
Dado que el populismo implica una crítica radical de la democracia representativa, a la que ve como materialización de la división entre élites y pueblo - representantes y representados- (Rivero, 2017: 35), se apela al poder constituyente materializado en el pueblo y a su capacidad de refundar la sociedad, si bien con el fin último de concentrar el poder en el Ejecutivo (De la Torre, 2018: 181), permitiendo al líder superar los límites y controles que impone la representación.

Como para el populismo los representantes forman una élite corrupta, la única manera que concibe de tener una verdadera democracia es enajenar el poder de las élites y devolvérselo al pueblo, el cual, a su vez, se lo transmitirá al líder, quien materializará la voluntad popular. Por ello, el populismo, si bien afirma no tener otro objeto que darle el poder al pueblo, no hace más que servirse instrumentalmente de él para fortalecer al líder. Renegar de las instituciones representativas, apelar al pueblo reunido en la plaza pública y apoderarse de la legitimidad de él emanada para ofrecérsela por aclamación al líder no es un descubrimiento contemporáneo y puede ser rastreado, entre otros, en el fascismo o el nacionalsocialismo durante el periodo de entreguerras. Conocida es la crítica de Sartori (2007: 125-131) al recurso a referendos y plebiscitos, que, indica, multiplica los problemas y es una puerta abierta al demagogo que pone en peligro la democracia.

\section{El enemigo}

El populismo dota de un poder extraordinario al líder para que pueda salvar al pueblo del enemigo. El enemigo del pueblo (Weyland, 2013: 21) puede ser interno o externo, concreto o difuso. Las élites políticas y económicas fueron el enemigo habitual para los populismos de finales del siglo xIX y principios del siglo Xx (Mudde y Rovira, 2017: 6) y siguen siendo el enemigo más recurrente del populismo en la mayoría de los análisis actuales (Rivero, 2017: 34). Enemigo pueden ser también los inmigrantes, refugiados y extranjeros, un país determinado o, incluso, el capitalismo internacional. El enemigo puede ser cualquiera, pero ha de haber un enemigo con el que no es posible negociar, solo cabe luchar y solo el líder capitaneando al pueblo puede imponerse a él. La existencia de un enemigo es crucial para el populismo porque una ruptura populista solo se produce cuando ha tenido lugar una dicotomización del espacio social en la que los ciudadanos se ven a sí mismos como miembros de dos campos enfrentados (Laclau, 2006: 56).

\section{El rechazo al acuerdo}

Dado que el pueblo es una unidad, fuera de él solo puede habitar el enemigo. Esta es «la lógica schmittiana del populismo» (De la Torre, 2017: 140; 2018: 192). Con el enemigo no es posible pactar. No cabe concebir la política como un proceso de cesiones y transacciones, sino como una lucha en la que solo puede llegarse a la victoria 
o a la derrota; donde uno ha de imponerse al otro, establecer su hegemonía y materializar sus objetivos. El populismo rechaza las instituciones representativas, instrumento para el acuerdo entre rivales, al verlas como herramienta de las élites para hurtar el poder al pueblo (Bonikowski y Gidron, 2016: 7). Ejemplo de este modo de concebir la política es la forma en la que, en el marco del debate político estadounidense, se ha denunciado que Trump negocia, comparándola con un secuestro con rehenes en el que el secuestrador es Trump, aquel que debe pagar el rescate la otra parte y los rehenes cualquiera que esté bajo el poder del presidente. Así, en la negociación con el Congreso sobre los inmigrantes se acusó a Trump de usar como rehenes a las familias que al cruzar la frontera son separadas (Chait, 2018).

\section{El ideal}

El populismo trata de volver a un pasado glorioso o alcanzar un futuro utópico. No cabe conformarse con reformas sociales parciales ni es aceptable realizar los cambios que la sociedad requiere de un modo progresivo. Hay que echar abajo la podrida sociedad actual y, desde cero, construir una nueva sociedad que carezca de todo defecto. El populismo gusta de presentarse «como subversivo del estado de cosas existente y también como el punto de partida de una reconstrucción más o menos radical de un nuevo orden" (Laclau, 2005: 221). Las fuerzas populistas, tanto antes de alcanzar el poder como una vez alcanzado, acostumbran a defender la necesidad de refundar la sociedad realizando una nueva constitución que dé comienzo a una diferente etapa nacional, lo que puede desembocar no en textos de consenso, sino en textos partisanos que busquen perpetuar al líder y al movimiento populista en el poder (Müller, 2016a: 4-5, 67-68). Señala Popper (2010: 400 y ss.), y quepa aplicarlo al populismo, que uno de los rasgos que diferencia a la sociedad abierta de la cerrada es la concepción holística que tiene la segunda (a la que identifica con el totalitarismo) de las transformaciones sociales, a las que no ve como un proceso gradual, sino como un cambio brusco.

\section{La emoción}

El populismo no apela a la razón, sino a la emoción. No se dirige al cerebro de los votantes, sino a su corazón. Es habitual representar al votante populista como aquel que responde a estímulos más emocionales que racionales, pero no debe ignorarse a Müller (2016b: 60) cuando critica la relación necesaria entre los estados psicológicos dominantes de los votantes y su opción política, pues generalizar que todos los votantes del populismo son perdedores de la globalización que sienten más que razonan sería como decir que todos los votantes socialdemócratas son trabajadores envidiosos de los ricos. El populismo no ofrece tanto argumentos racionales, como consignas maximalistas. No duda en recurrir a las pasiones, alentando en no pocas ocasiones los más bajos instintos de los ciudadanos. Se argumenta, por ejemplo, que desde que Trump 
llegó al poder, el tribalismo, la división de la sociedad estadounidense en grupos de carácter racial, cultural o incluso lingüístico, vive un momento de auge (Felton, 2018).

Se habla de los hechos alternativos, que acostumbran a ser la versión subjetiva y generalmente falsa que de los hechos (objetivos) tienen sujetos particulares. Se relativiza la verdad, se ponen en duda las afirmaciones científicamente probadas y se deslegitima a los intelectuales a los que se acusa de engañar al pueblo y estar al servicio de poderes económicos o políticos interesados. Esta deslegitimación de los intelectuales parece encajar con la idea de que el votante populista tiene escasa formación y por ello desconfía de los que sí la tienen. Así, en el referéndum británico sobre la permanencia en la UE se comprobó que gran parte de los votantes pro brexit o no tenían cualificaciones o tenían un escaso nivel educacional: quince de las veinte áreas con menor nivel de formación del Reino Unido votaron a favor del brexit, mientras que las veinte más formadas votaron por continuar en la UE (Goodwin y Heath, 2016: 115).

\section{La oposición a la limitación del poder}

Dado que el líder habla en nombre del pueblo, no cabe limitar el poder del líder, pues hacerlo supondría limitar el poder del pueblo. El populismo erosiona los controles que existen para limitar el poder ejecutivo, tanto los ejercidos por los otros poderes del Estado como los que pueda hacer la prensa o las organizaciones de la sociedad civil. El populismo no es pluralista (Müller, 2016a: 3 y 101), concentra el poder y tiene tendencia al autoritarismo (De la Torre, 2017: 133-134). Suele llevar a que la democracia desaparezca o quede desfigurada, si bien no súbitamente, como en un golpe de Estado militar, sino progresivamente, como un lento estrangulamiento (De la Torre, 2018: 190-191). El antagonismo entre liberalismo — como ideología que busca la limitación del poder-y populismo se sintetiza en el diferente grado de limitación del poder del líder: en el primero el líder no es más que un representante de la ciudadanía que ocupa un cargo limitado constitucionalmente en sus facultades y en el tiempo; en el segundo, el líder, como encarnación del pueblo, tiende a exceder todo límite constitucional llegando a situarse por encima de todo límite constitucional. No es extraño en el populismo demandar sucesivas reformas constitucionales que adapten el texto constitucional a la cada vez mayor ambición de poder material y temporal del líder. Sin embargo, como indica Popper (2010: 339), la virtud crucial de la democracia es contener y equilibrar el poder. De ahí el imposible maridaje entre populismo y democracia liberal.

\section{El rechazo del librecambio}

El populismo crea nuevas fronteras y las fortalece allí donde ya existen, y ello mientras afirma proteger con ello al pueblo. Por ello, el librecambio, al permitir 
que el capital y, en menor medida, los trabajadores extranjeros puedan moverse con libertad, penetrar en el país y romper la unidad del pueblo es visto como un riesgo que debe ser controlado y, si es posible, extirpado. De ahí que el populismo opte por renegociar los tratados de libre comercio o salirse de ellos -Alternativa por Alemania denuncia que los tratados de libre comercio dañan el derecho nacional y se opone a algunos como el TTIP, el TISA y el CETA (AfD, 2017) —; opte por el proteccionismo e imponga aranceles, provocando subidas de precios que perjudican a los consumidores - los aranceles impuestos por Trump encarecieron el precio de las lavadoras una media de cien dólares (Zilber, 2019)_; se oponga al movimiento internacional de las empresas y de los trabajadores, y defienda una cierta autarquía en la economía nacional. Especialmente es hostil con los inmigrantes, a los que acusa de robar los trabajos de los nacionales o perjudicarles bajando los sueldos y los derechos sociales: la web de la Casa Blanca, bajo el epígrafe "Inmigración», relaciona su limitación con la protección de los trabajadores americanos (White House, 2019), y la Liga en Italia utiliza publicidad electoral con lemas como "Stop Invasione» en referencia a la alegada invasión de inmigrantes (Leganord, 2019).

\section{Nacionalismo}

El populismo plantea una concepción unitaria del pueblo y una idealización del pasado que le lleva a interpretar la historia de un modo interesado; además, su identificación habitual del enemigo con lo extranjero hace que el populismo sea normalmente nacionalista. Busca recuperar la soberanía supuesta o efectivamente perdida, ya sea rompiendo los acuerdos internacionales y aislando al país, ya tratando de independizar regiones de un Estado al aplicar a una menor escala territorial los mismos principios. En esta clave de recuperación de soberanía cabe entender algunas de las promesas electorales - 96 y $99-$ del partido Vox para las elecciones de 2019 (Vox, 2019), o lemas electorales como Take back control («recuperar el control»), que usaron los defensores del brexit (Goodwin y Heath, 2016: 114). Los lemas electorales de Trump, America first ("América primero») y Make America great again («Hacer América grande de nuevo»), resumen un nacionalismo que cree que el mundo exterior le agrede. Lemas que han sido relacionados con los usados por los grupos antisemitas y nazis estadounidenses de los años treinta y cuarenta (Calamur, 2017). Este nacionalismo suele concretarse en el deseo de fortalecer las fronteras frente a la denunciada invasión de extranjeros, no siendo extraño que el fortalecimiento fronterizo se materialice en la propuesta de construir muros. El más famoso es el muro con México propuesto por Trump, pero en Europa no son pocos los partidos que defienden esta misma respuesta a la inmigración. En España, en la propuesta electoral de su programa electoral de 2019 Vox propone construir sendos muros infranqueables en Ceuta y Melilla (Vox, 2019). 


\section{El fin de las ideologías tradicionales ${ }^{7}$}

El populismo no suele ordenarse alrededor de un partido político convencional, sino, al menos en principio, de un movimiento ciudadano. Acostumbra a superar la dualidad derecha/izquierda (Judis, 2016: 14) para incardinarse en un binomio de pueblo/antipueblo que se puede enmarcar en la oposición intrasistema/extrasistema, entendiendo por lo primero la aceptación de la democracia liberal y del libre cambio mundializado, y por lo segundo la oposición a uno o a los dos elementos anteriores. Se vive en el presente una evolución del dualismo derecha-izquierda, propio de la segunda mitad del siglo xx, a un nuevo eje político en el que los partidos tradicionales de derecha e izquierda se coaligan formal o materialmente, mientras que frente a ellos aparecen nuevos movimientos políticos populistas que proponen modificar los elementos nucleares de la estructura política y/o de la económica. Como indica Vallespín (2015: 15), el surgimiento del populismo también puede leerse como la ocupación por nuevas fuerzas del espacio político que queda vacío al ser cada vez más similares en sus propuestas los tradicionales partidos de derecha e izquierda.

El populismo puede asumir formas de derechas o de izquierdas, en gran medida en función del país y de sus circunstancias concretas. El populismo de derechas puede atacar a los inmigrantes y el de izquierdas a las élites (Judis, 2016: 15). En la práctica, el populismo no tendrá problema en salir de esos márgenes porque, realmente, nunca los habita más allá de a nivel epidérmico. En palabras de Laclau (2006: 57): «Ideologías de la más diversa índole — desde el comunismo hasta el fascismo- pueden adoptar un sesgo populista». Al haber cambiado el eje de ordenación de la política, no es extraño que haya identidad de objetivos e incluso coaliciones entre populismos formalmente opuestos, adscritos a la derecha y a la izquierda, del mismo modo que cada vez más se produce el mismo fenómeno entre las antiguas derechas e izquierdas. En Italia se alían La Liga y el Movimiento 5 Estrellas en una coalición extrasistema, mientras que en Alemania lo hacen la CDU y el SPD en una coalición intrasistema.

En función de las características citadas se puede dar respuesta a algunas de las preguntas expuestas al comienzo de este texto. Así, cuando se planteaba si es posible que un partido identificado con la derecha o con la izquierda sea populista, la respuesta sería que sí, pero siempre que se asuma que ser de derecha o izquierda no será otra cosa más allá de una adscripción formal tras la que se encontrará la verdadera naturaleza populista del partido y, por tanto, ajena a esa dicotomía. Igualmente, se preguntaba qué es ser populista y si tal denominación no sería nada sino un calificativo peyorativo

7. La afirmación de que el populismo surge a raíz del fin de las ideologías tradicionales no ha de ser entendida como contradictoria con la consideración de que gran parte de lo que en el presente se considera populismo hunde sus raíces en los autoritarismos de entreguerras y en particular en el fascismo. Así, Krauze (2017: 19) indica que durante el siglo xx se produjo la transformación del caudillismo patriarcal típicamente latinoamericano en populismo a causa de la penetración de las ideas del fascismo italiano en el continente, personificando este fenómeno figuras como Getulio Vargas en Brasil o Perón en Argentina. 
sin mayor contenido que el de ser un insulto lanzado al rival político. Indican Bonikowski y Gidron (2016: 7-9) que el populismo acostumbra a ser visto desde tres puntos de vista no mutuamente excluyentes: como estrategia de movilización política, como forma de discurso político y como ideología. Desde estas líneas no se comparte concebir el populismo como un término sin concepto detrás, como un artificio del discurso político que no se identifica con ideología alguna ni posee mayor relevancia que la de ser un epíteto que se arroja al adversario. Por el contrario, se sostiene que el populismo es una ideología Una ideología que es contradictoria con la democracia liberal y que surge como oposición a las dinámicas aperturistas, pluralistas y multiculturales que la globalización genera. El populismo, más allá de que pueda ser usado como un cajón de sastre en el que quepa meter multitud de formaciones con variopintas identificaciones ideológicas de sí mismas, posee un elemento definitorio y siempre presente que es la reacción, en especial la reacción frente a la actual formulación globalizadora de la democracia liberal y de la economía librecambista (Ramírez Nárdiz, 2017: 23-25).

Dentro de la reacción a la globalización, frente a qué o quién se reaccione dependerá de cada partido populista. El enemigo debe existir, pero quién sea el enemigo es algo flexible. Lo más habitual es entender que el populismo enfrenta al pueblo con las élites (De la Torre, 2018: 180), pero en las formulaciones contemporáneas del populismo no parece que sea necesariamente así, sino que el populismo, fragmentando en dos grupos a la sociedad e indicando que una de esas dos mitades es el enemigo, puede hacer que dicho enemigo sean las élites, pero también sujetos ajenos a un grupo oligárquico, como los inmigrantes o cualquier otra minoría que sirva de chivo expiatorio para galvanizar al pueblo frente al enemigo. Puede también haber un enemigo dual: por un lado las élites, y por el otro ciertas minorías con las que esas élites sea alían (la prensa progresista con el lobby gay o con las feministas, los políticos de izquierdas con los inmigrantes, etc.). La existencia de un enemigo que permita personificar la reacción contra la globalización será una constante, pero que este sea o no la élite dependerá del partido o movimiento populista concreto, siendo la equiparación entre el enemigo y la oligarquía algo habitual, pero no imprescindible.

Aunque los enemigos sean aparentemente muy dispares, en última instancia acostumbran a no serlo tanto y tampoco hay tanta diferencia entre un populismo de izquierdas, opuesto al gran capital que deslocaliza empresas, y un populismo de derechas que denuncie a los trabajadores extranjeros. En última instancia ya las empresas, ya los extranjeros, son dos aspectos de la misma cosa: la globalización y sus efectos. Por ello, si algo es el populismo, es una reacción frente a la globalización. Si la globalización supone apertura de fronteras, multiculturalismo y extensión del librecambio y de la democracia liberal, el populismo es la respuesta a ello de todos los (que se consideran) perjudicados: desempleados, culturas minoritarias, grupos sociales dominantes que ven menguar su poder, etc. Como indica Müller (2016b: 59), no siempre los votantes del populismo encajan en el perfil de hombres blancos, pobres y de escasa educación. El votante populista puede tener una buena situación 
económica y votar populista no por el desempleo, sino por otros factores como su visión crítica de las élites y de la evolución nacional. Además, los partidos populistas pueden llegar a ser tan grandes que acaben siendo partidos atrápalo todo votados por todo tipo de ciudadanos.

El populismo no sería tanto un algo, sino un antialgo, pero ser un antialgo no es contradictorio con ser una ideología; por ello, es posible definir al populismo como una ideología reactiva cuya razón de ser es oponerse a la globalización y a sus efectos. Esta concepción del populismo como una ideología reactiva a la globalización como forma contemporánea de la democracia liberal y del liberalismo económico (Ramírez Nárdiz, 2018: 173-174), no contradice la concepción tradicional del populismo que gira alrededor de tres elementos básicos: pueblo virtuoso, élites corruptas y líder mesiánico, sino que parte de ella para aportar una definición del populismo adaptada a la realidad contemporánea.

Como reacción frente a la globalización, frente a la apertura de sociedades y economías, el populismo aparece como una regresión con tintes tribales, el intento de cerrar fronteras, purificar racial, religiosa o culturalmente un país y volver a un pasado edénico o alcanzar un futuro utópico en el que la comunidad se realice merced a una uniformización en la que fuera solo haya enemigos y dentro una única masa de individuos sometidos a la voluntad de un líder que dice hablar en su nombre. Entendido así y aplicándole las categorías de Popper (2010: 407), el populismo, como en su día el totalitarismo, podría explicarse como una nueva reacción de la sociedad cerrada (tribal, irracional, mágica) frente a la globalización como último progreso de la sociedad abierta (democrática, racional, científica). Pero estas reflexiones exceden los objetivos de este texto y no deben ir más allá.

\section{IDEOLOGÍA DE TRUMP VERSUS CARACTERÍSTICAS DEL POPULISMO}

Expuestos los rasgos más significativos del pensamiento de Trump y propuestas las características más relevantes del populismo, corresponde compararlos tratando de discernir si existe o no identidad entre unos y otras y, en el caso de que exista, si dicha identidad es tal que permita considerar a Trump un populista.

De la comparativa realizada puede concluirse que sí existe una identidad bastante marcada entre la ideología de Trump y la propuesta de características que se hace en este texto del populismo. Por supuesto, no todos los elementos de la ideología de Trump han de ser necesariamente populistas o exclusivamente populistas, pero sí que parece manifiesto que gran parte de los elementos del pensamiento de Trump encuentran su equivalente en el populismo. El populismo se adapta al contexto nacional de cada Estado, pudiendo llegar a adoptar formas aparentemente contradictorias entre sí, pero siempre tiene una serie de rasgos definitorios comunes (el líder, el buen pueblo, el enemigo, la reacción a la apertura económica, social y cultural que la globalización supone, etc.) que en el caso Trump no parece errado considerar que se dan. Trump ha llevado al populismo al centro de la política 
estadounidense y a la presidencia de las EE. UU. (De la Torre, 2018: 179), pero, si bien pudiera considerarse que el populismo de Trump no es más que una forma de «anti-establishment» (Müller, 2016b: 58), lo que se extrae del análisis precedente es que, pudiendo ser tenido por tal cosa en la forma, en el fondo es algo que va más allá, algo que, de hecho, tiene fondo y no solo forma, y que es una ideología.

Tabla 1.

Comparativa entre la ideología de Donald Trump y el populismo

\begin{tabular}{cc}
\hline Ideología de Donald Trump & Características del populismo \\
\hline La reacción: supremacismo cultural, & El pueblo como unidad; el enemigo; el ideal; \\
xenofobia, racismo, machismo & fin de las ideologías tradicionales; nacionalismo \\
\hline
\end{tabular}

Relación: Trump identifica al pueblo de los EE. UU. con una unidad de gente buena - WASP-, amenazada por enemigos internos (élites económicas, políticas y culturales en cooperación con parte de la prensa) y por enemigos externos (extranjero, inmigrantes, refugiados, terroristas, México, China o Alemania). Se afirma buscar la recuperación de un pasado ideal en el que el trabajador industrial (hombre, blanco, anglosajón) era el grupo dominante. Trump supone la reacción del grupo tradicionalmente dominante frente a los otros grupos (mujeres, otras nacionalidades, razas, religiones) que ponen en peligro su dominio merced a los cambios introducidos por la globalización. Se rompe la dualidad derecha/izquierda y se pasa a una nueva ordenación ideológica que enfrenta a intrasistémicos (apoyan la democracia liberal y los cambios generados por la globalización) y extrasistémicos (se oponen a los cambios que la globalización supone y reaccionan proponiendo un nuevo modelo político que se tiene por democrático, pero que es populista), entre los cuales se encuentra Trump.

\section{Proteccionismo económico Rechazo del librecambio}

Relación: Trump indica que el librecambio internacional perjudica a EE. UU. China, Alemania, México o Canadá son los culpables. La respuesta es renegociar los tratados de libre comercio (amenazando con salir de ellos) haciéndolos más restrictivos, imponer aranceles —en ocasiones, como forma de represalia- y exigir a las grandes empresas deslocalizadas su vuelta a EE. UU. bajo amenaza de multas y subidas de impuestos. Se apuesta por el proteccionismo y por privilegiar a las empresas nacionales. El resultado es el aumento de los precios de los productos de consumo, la pérdida de empleos y la caída del comercio internacional.

\begin{tabular}{l} 
Aislacionismo, unilateralismo, militarismo Rechazo del acuerdo; nacionalismo; el enemigo \\
\hline Relación: Trump tensa las relaciones con los aliados tradicionales de EE. UU., practica una \\
política internacional de imposiciones (subida de gasto militar de sus aliados, construcción \\
del muro con México), sale de tratados internacionales como el Acuerdo del Clima, amenaza \\
con salir de otros como los de libre comercio, realiza ataques (Siria) de modo unilateral, \\
amenaza a países con la destrucción (Corea del Norte). Su lema America First es la materiali- \\
zación del nacionalismo. Un nacionalismo en el que se denuncia que EE. UU. lleva mucho \\
tiempo perdiendo y que es hora de que gane, es decir, que deje de llegar a acuerdos (con bene- \\
ficios para ambas partes) y comience a logar victorias. Plantea las relaciones internacionales \\
como una herramienta para ubicar al enemigo y enfrentarse a él, no por la necesidad nacional, \\
sino por la suya como líder populista que requiere de la existencia de un enemigo para justi- \\
ficar su acción de gobierno.
\end{tabular}




\begin{tabular}{|c|c|}
\hline & Características \\
\hline Negacionismo, antiintelectualismo & $\begin{array}{l}\text { deologías } \\
\text { in al pueblo; } \\
\text { d }\end{array}$ \\
\hline \multicolumn{2}{|c|}{$\begin{array}{l}\text { Relación: Trump apela a los sentimientos de los ciudadanos, no a su razón, despreciando a } \\
\text { los intelectuales y los estudios científicos (ej. cambio climático), relativizando los hechos al } \\
\text { contraponerlos con los hechos alternativos. Se encuadra en el Partido Republicano, pero no } \\
\text { encaja en la ortodoxia del partido, trasciende la dualidad tradicional entre republicanos y } \\
\text { demócratas y se dirige al americano medio empobrecido por los cambios sociales de las últimas } \\
\text { décadas, al que le promete la sociedad ideal perdida, aquella en la que el pueblo era una } \\
\text { unidad, gente buena, los WASP monopolizando el poder. Ofrece la felicidad perdida (un } \\
\text { sentimiento, un ideal), rechaza la razón, los hechos y busca identificarse con la ciudadanía } \\
\text { como un todo uniforme. }\end{array}$} \\
\hline & \\
\hline \multicolumn{2}{|c|}{$\begin{array}{l}\text { Relación: tanto en el personaje que encarna (triunfador, hecho a sí mismo, rebelde frente a } \\
\text { los poderosos, sincero en su relación con la gente, políticamente incorrecto), como en el tipo } \\
\text { de líderes por los que expresa respeto y admiración (Putin, Xi, Erdogan), Trump muestra una } \\
\text { concepción de la política caudillista en la que el líder excede el marco de administrador } \\
\text { elegido por los ciudadanos y se convierte en un guía, un mesías de su pueblo. Pueblo en el } \\
\text { cual se legitima para justificar su resistencia a someterse a la separación de poderes y a la limi- } \\
\text { tación del poder que exige la democracia liberal. Pueblo al que solo él representa (al menos, } \\
\text { al pueblo al que desde su perspectiva merece la pena considerar por tal: pueblo WASP), en } \\
\text { cuyo nombre él habla y que protege frente al enemigo. }\end{array}$} \\
\hline
\end{tabular}

Fuente: elaboración propia.

\section{CONCLUSIONES}

Comparados los rasgos examinados de la ideología de Donald Trump y la propuesta realizada de características del populismo es posible afirmar que sí existe una identidad entre ambos que permite afirmar que el actual presidente de EE. UU. es populista. Incluso en algunos aspectos podría ser considerado el paradigma mismo del populista si se acepta por tal aquel que focaliza el poder en su persona; que debilita las instituciones representativas; que divide y polariza el país; que encona las disputas buscando enemigos reales o ficticios; que se opone a la apertura tanto de fronteras sociales como culturales; que en sí supone una reacción a la globalización, y que, aunque formalmente asume una determinada ideología clásica, en la práctica se enmarca en una nueva dicotomía en la que el eje ideológico ya no es el de derecha e izquierda, sino el de favorables o no a la democracia liberal y al libre mercado globalizado, es decir, intra o extrasistémicos. El populismo de Trump no puede ser considerado como una postura de mercadotecnia, un artificio de un promotor inmobiliario y hombre del espectáculo reconvertido en líder político; incluso pese a que el propio 
personaje lo pueda creer así. De hecho, más allá de las palabras y de las opiniones están los hechos, y los hechos del presidente de EE. UU., sus medidas, sus propuestas y decisiones son claramente populistas en función de lo aquí analizado.

¿Por qué se puede afirmar que Trump es populista? Más allá de una identificación de los distintos elementos de su ideología con las características propuestas del populismo, lo que permite identificar al hombre con el movimiento es la coincidencia esencial en el núcleo del discurso de ambos, que no es otra que la oposición a la globalización y sus efectos. Trump no solo es populista porque sus actuaciones coinciden con varios de los rasgos del populismo, sino porque la esencia de su propuesta es la misma que la del populismo: la reacción a la democracia liberal y a su forma contemporánea (multicultural, internacional, plural, abierta) en la globalización. Esto es lo que hace que diversos partidos y líderes alrededor del mundo con ideologías aparentemente contradictorias puedan ser considerados como populistas. Más allá del destino concreto de sus iras, todos tienen un enemigo común que es la apertura económica, política y social que supone la globalización en la que vive el mundo en las últimas décadas. Por eso, el Movimiento 5 Estrellas y la Liga pueden gobernar en coalición en Italia; porque aunque ambos procedan de orígenes aparentemente distintos, son populistas como Trump; es decir, enemigos de la globalización.

¿Cuál es el remedio frente a figuras como Trump y ante el auge del populismo en Europa y América? Sin voluntad de desarrollar tal cuestión, que excede el espacio de este texto, es posible destacar que la solución, pese a no ser una ni sencilla, ha de pasar necesariamente por la defensa y la profundización de la democracia liberal; es decir, una defensa de sus valores, particularmente la limitación del poder y el pluralismo (anatemas para el populismo) y una profundización en su ejercicio efectivo, quizá mediante instrumentos participativos y sin renunciar al alma social de las actuales democracias, la cual ha demostrado su utilidad para evitar que parte de la ciudadanía opte por opciones alternativas a la democracia liberal. No se debe olvidar que el populismo entendido como una ideología no es compatible con la democracia liberal. Sus características no encajan, sus elementos chocan. El populismo no es una mera forma que se superponga sin transformar el fondo democrático; al contrario, su naturaleza le lleva a desvirtuar primero y deshacer después el acervo democrático, llevando a un modelo que no comparte nada con la democracia liberal, salvo el nombre. Si se desea defender la democracia, no queda más opción que denunciar el populismo.

\section{Referencias}

Abad Quintanal, Gracia. 2017. «Las relaciones entre Estados Unidos y la República Popular China en la era Trump: el arte de la negociación frente al arte de la Guerra», Revista Española de Derecho Internacional, 69 (2): 317-323. Disponible en: https://doi.org/10.17103/redi.69.2.2017.2.05.

AfD. 2017. Manifesto for Germany. Disponible en: http://bit.ly/2TEJ70R. 
Aguilar Rivera, José A. 2019. «Tocqueville y el populismo», Noesis, 28 (55-1): 61-74. Disponible en: https://doi.org/10.20983/noesis.2019.3.4.

Albright, Madeleine. 2018. Fascism: a warning. Nueva York: Harper Collins.

Almansa Pérez, Rosa M. 2019. «El populismo de extrema derecha en los Estados Unidos de la era Trump: de la democracia "sin rostro" a la reacción identitaria", Anales de la Cátedra Francisco Suárez, 53: 157-181. Disponible en: https://doi. org/10.30827/acfs.v53i0.7947.

Ayuso, Silvia. 2016. "Donald Trump llama "asquerosa" a Alicia Machado, la inmigrante a la que humilló", El País, 1-10-2016. Disponible en: http://bit.ly/3aXCtZF.

Bassets, Marc y Joan Faus. 2017. «Trump veta la entrada de refugiados e inmigrantes de varios países musulmanes», El Pais, 17-4-2017. Disponible en: http://bit.ly/39JFfkN.

Bierman, Noah. 2017. «Trump warns North Korea of fire and fury», Los Ángeles Times, 8-8-2017. Disponible en: https://lat.ms/2Q84DJd.

Bonikowski, Bart y Noam Gidron. 2016. «Multiple traditions in Populism research: toward a theoretical synthesis», Comparative Politics Newsletter, 26 (2): 7-14. Disponible en: https://doi.org/10.2139/ssrn.2875372.

Broonfield, Matt. 2016. «9 standout quotes from the Republican debate (And Donald Trump was responsible for five of them)», Independent, 14-2-2016 de febrero. Disponible en: http://bit.ly/2IFAigU.

Calamur, Krishnadev. 2017. «A short history of America First», The Atlantic, 21-12017. Disponible en: http://bit.ly/2IFM2jv.

Chait, Jonathan. 2018. «Why Trump Is Using Hostage Tactics on Family Separation", New York Magazine, 18-6-2018. Disponible en: https://nym.ag/2W6cDhx.

Chan, Melissa. 2016. «Donald Trump Claims Black and Hispanic People Are 'Living in Hell'», Fortune, 26-10-2016. Disponible en: http://bit.ly/2W2Ncxr.

Cheathem, Mark R. 2017. «Donald Trump is not a Twenty-First Century Andrew Jackson", The American Historians, Disponible en: http://bit.ly/2THTmBK.

Cillizza, Chris. 2017a. «Donald Trump's incredibly unpresidential statement on Charlottesville», CNN Politics, 13-8-2017. Disponible en: https://cnn.it/33h05pq.

Cillizza, Chris. 2017b. «Donald Trump doesn't think much of climate change, in 20 quotes», CNN politics, 8-8-2017. Disponible en: https://cnn.it/3aKhxF3.

CNN. 2017. Asesora de Trump: Casa Blanca citó "hechos alternativos» sobre asistencia a toma de posesión. Disponible en: https://cnn.it/2IJsLh3.

De la Torre, Carlos. 2013. «El populismo latinoamericano: entre la democratización y el autoritarismo", Nueva Sociedad, 247: 120-137.

De la Torre, Carlos. 2017. «Los populismos refundadores. Promesas democratizadoras, prácticas autoritarias», Nueva Sociedad, 267: 129-141.

De la Torre, Carlos. 2018. «Leyendo a Donald Trump desde América Latina», Revista SAAP: Sociedad Argentina de Análisis Politico, 12 (1): 179-194.

Diamond, Jeremy. 2016. «Trump slams globalization, promises to upend economic status quo», CNN Politics, 28-6-2016. Disponible en: https://cnn.it/33abgjo.

Eilperin, Juliet y Darla Cameron. 2018. «How Trump is rolling back Obama's legacy», The Washington Post, 30-1-2018. Disponible en: https://wapo.st/2THEiny. 
Feller, Daniel. (2019). The Papers of Andrew Jackson. About Andrew Jackson, Knoxville: The University of Tennessee. Disponible en: http://bit.ly/39JuQWr.

Felton, Lena. 2018. "Can America Survive Tribalism?», The Atlantic, 31-5-2018. Disponible en: http://bit.ly/2TYM37s.

Goodwin, Matthew y Oliver Heath. 2016. «Brexit, populism and the 2016 UK Referendum to leave the EU», Comparative Politics Newsletter, 26 (2): 113-116.

Hawkins, Kirk. 2016. «Populism and the 2016 U.S. Presidential Election in comparative perspective», Comparative Politics Newsletter, 26 (2): 91-97.

Ivarsflaten, Elisabeth. 2016. "Siren songs: reflections on contemporary populism in Europe's old democracies». Comparative Politics Newsletter, 26 (2): 50-52.

Judis, John B. 2016. The populist explosion. Nueva York: Columbia Global Reports.

Kazin, Michael. 2016. «Trump and American Populism. Old Whine, New Bottles», Foreign affairs. Disponible en: https://fam.ag/2wNaFbz.

Krauze, Enrique. 2017. "Arqueología del populismo», en Ángel Rivero (coord.), Geografia del populismo. Un viaje por el universo del populismo desde sus orígenes hasta Trump. Madrid: Tecnos.

Laclau, Ernesto. 2005. La razón populista. Buenos Aires: Fondo de Cultura Económica.

Laclau, Ernesto. 2006. "La deriva populista y la centroizquierda latinoamericana», Nueva sociedad, 205: 56-61.

La Vanguardia. 2016. «El vídeo más machista y grosero de Donald Trump sale a la luz», La Vanguardia, 8-10-2016. Disponible en: http://bit.ly/38NGb6E.

Leganord. 2019. Stop Invasione. Disponible en: leganord.org/stopinvasione.

Lowndes, Joseph. 2016. «Populism in the 2016 U. S. election», Comparative Politics Newsletter, 26 (2): 97-101.

Martín, Carolina. 2017. «Trump retira las ayudas de Obamacare para las personas con menos recursos", El Mundo, 13-10-2017. Disponible en: http://bit.ly/39MysqA.

Mead, Walter R. 2016. «Donald Trump's Jacksonian Revolt», Hudson Institute, 13-11-2016. Disponible en: http://bit.ly/38I0C4T.

Mead, Walter R. 2017. «The Jacksonian Revolt», Hudson Institute, 20-1-2017. Disponible en: http://bit.ly/2TGvu19.

Mena, Tomás. 2018. "Donald J. Trump: A critical discourse analysis», Estudios Institucionales, 5 (8): 47-73. Disponible en: https://doi.org/10.5944/eeii. vol.5.n.8.2018.21778.

Moffitt, Benjamin. 2016. «The performative turn in the comparative study of populism», Comparative Politics Newsletter, 26 (2): 52-58.

Moye, David. 2018. "Howard Stern tells how Trump sexualized Ivanka and makes David Letterman cringe», Huffpost, 21-5-2018. Disponible en: http://bit.ly/2viqQNG.

Mudde, Cas. 2004. «The populist zeitgeist», Government and opposition, 4: 541-563. Disponible en: https://doi.org/10.1111/j.1477-7053.2004.00135.x.

Mudde, Cas y Cristóbal Rovira. 2013. «Exclusionary vs. inclusionary populism: Comparing contemporary Europe and Latin-America", Government and opposition, 48 (2): 147-174. Disponible en: https://doi.org/10.1017/gov.2012.11. 
Mudde, Cas y Cristobal Rovira. 2017. Populism. A very short introduction. Nueva York: Oxford University Press. Disponible en: https://doi.org/10.1093/actrade/ 9780190234874.001 .0001$.

Müller, Jan W. 2016a. What is populism? Philadelphia: University of Pennsylvania Press. Müller, Jan W. 2016b. «How to think —and how not to think- about populism», Comparative Politics Newsletter, 26 (2): 58-62.

Politico Magazine. 2016. The 155 craziest things Trump said this election. Disponible en: https://politi.co/2TVo4Gl.

Popper, Karl. 2010. La sociedad abierta y sus enemigos. Barcelona: Paidos Ibérica.

Qiu, Linda. 2016. «Donald Trump's top 10 campaign promises», Politifact, 15-72016. Disponible en: http://bit.ly/2TVy5Ds.

Ramírez-Nárdiz, Alfredo. 2017. Guía urgente para entender y curar el populismo. Barcelona: J. M. Bosch. Disponible en: https://doi.org/10.2307/j.ctvrzgxm1.

Ramírez-Nárdiz, Alfredo. 2018. "Propuesta de definición del populismo desde el pensamiento de Karl R. Popper», Revista Española de Ciencia Politica, 48: 153-179. Disponible en: https://doi.org/10.21308/recp.48.06.

Raymond, Adam. 2018. «Trump doesn't get why U.S. has to defend NATO allies», New York Magazine, 18-7-2018. Disponible en: https://nym.ag/3aMQdGl.

Rivero, Ángel. 2017. «Populismo: ¡cómo destruir la democracia en nombre de la democracia?», en Ángel Rivero (coord.), Geografía del populismo. Un viaje por el universo del populismo desde sus orígenes hasta Trump. Madrid: Tecnos.

Rodrik, Dani. 2012. La paradoja de la globalización. Barcelona: Antoni Bosch Editor. Sartori, Giovanni. 2007. ¿Qué es la democracia? México, D. F.: Taurus.

Smith, David. 2016. "Populism, nationalism and U.S. foreign policy», Comparative Politics Newsletter, 26 (2): 101-106.

Stracqualursi, Veronica. 2017. «10 times Trump attacked China and its trade relations with the US", $A B C$ News, 9-11-2017. Disponible en: https://abcn.ws/2TI5ouX.

Tani, Maxwell. 2016. «I don't mean just a little bit better: Donald Trump threatens to leave NAFTA if elected», Business Insider, 28-6-2016. Disponible en: http://bit. ly/2U3210C.

Trump, Donald. 2017. «Statement by President Trump on the Paris Climate Accord», The White House. Disponible en: http://bit.ly/2Q6aIpA.

Vallespín, Fernando. 2015. «Las transformaciones de la democracia», Actualidad Jurídica Uria Menéndez, 41: 7-17.

Verdú, Daniel. 2018. "Italia se prepara para un cóctel antiestablishment», El País, 11-5-2018. Disponible en: http://bit.ly/2Q4H1Fk.

Vox. 2019. 100 medidas para la España viva. Disponible en: http://bit.ly/2WaAwF3.

Weyland, Kurt. 2001. "Clarifying a contested concept: Populism in the study of Latin American politics», Comparative politics, 34 (1): 1-22. Disponible en: https://doi. org/10.2307/422412.

Weyland, Kurt. 2013. «Latin America's authoritarian drift. The threat from the populist left», Journal of Democracy, 24 (3): 18-32. Disponible en: https://doi. org/10.1353/jod.2013.0045. 
White House. 2019. Immigration. Disponible en: http://bit.ly/3aQvMsd.

Woolf, Nicky. 2016. “Nasty woman”: Trump attacks Clinton during final debate», The Guardian, 20-10-2016. Disponible en: http://bit.ly/39H3srT.

Zilber, Ariel. 2019. «Trump tariffs have made washing machines almost $\$ 100$ more expensive as new study claims the price of dryers has also gone up", Daily Mail, 30-4-2019. Disponible en: http://dailym.ai/33bIQpa.

Presentado para evaluación: 22 de junio de 2019.

Aceptado para publicación: 31 de enero de 2020.

\begin{abstract}
ALFREDO RAMÍREZ NÁRDIZ
alfredoramireznardiz@hotmail.com

Es doctor en Derecho de la Universidad de Alicante y profesor de Derecho Constitucional de la Facultad de Derecho y Ciencias Sociales de la Universidad Libre, Barranquilla, Colombia. Está acreditado como profesor contratado doctor por la ANECA (España) y como investigador senior por Colciencias (Colombia). Ha realizado más de cuarenta publicaciones académicas y presentado más de ochenta ponencias a congresos nacionales e internacionales. Es colomunista de opinion de El Heraldo de Barranquilla.
\end{abstract}

